\title{
The Role of Climatic Anomalies and Soil Moisture in the Decline of Drought-Prone Forests
}

\author{
David Chaparro, Student Member, IEEE, Jordi Vayreda, Mercè Vall-llossera, Senior Member, IEEE, Mireia Banqué, \\ Maria Piles, Member, IEEE, Adriano Camps, Fellow, IEEE, and Jordi Martínez-Vilalta
}

\begin{abstract}
Increased intensity and duration of droughts and high-temperature events have been associated with forest decline in many parts of the world, and these decline events are expected to become more common under climate change. There is, therefore, a need for monitoring and modeling of forest decline. We used a regional forest condition monitoring program (DEBOSCAT) to study the spatial distribution of decline events in 2012 in Catalonia (Northeastern Spain) and their relationship with climatic factors. In 2012, this dataset was collected after an extraordinarily dry summer, and allowed the study of decline events in eight dominant tree species. We fitted a logistic model to predict forest decline probability as a function of species, precipitation and temperature anomalies, solar radiation, and remotely sensed soil moisture data from the Soil Moisture and Ocean Salinity Mission (SMOS). Broadleaved species were more affected by decline events than conifers. The statistical model explained almost $40 \%$ of forest decline occurrence, wherein almost $50 \%$ of this variability was explained by species effect, with broadleaved trees being generally more sensitive to the studied factors than conifers. Climatically wetter areas and those more exposed to radiation were more likely to be affected, suggesting better adaptation of forests in dry areas. In general, more damaged forests were characterized by high-positive temperature anomalies, lower than average rainfall, and low soil moisture in summer 2012. The most vulnerable species was Fagus sylvatica, a Euro-Siberian species, contrasting with $P$ inus halepensis, a typically Mediterranean species, which showed low sensitivity to drought.
\end{abstract}

Manuscript received February 26, 2016; revised April 26, 2016 and May 30, 2016; accepted June 11, 2016. This work was supported by the Spanish Government through the DRIM Project (CGL2010-16373), the FUN2FUN Project (CGL2013-46808-R), the Project PROMISES: Productos y servicios innovadors con sensores de microondas, SMOS y Sentinels para tierra (ESP2015-67549C3-1-R), and the Predoctoral Grant Ayudas para contratos predoctorales para la Formación de Doctores, with reference BES-2013-066240, and was also supported by the European Regional Development Fund. (Corresponding author: David Chaparro.)

D. Chaparro, M. Vall-llossera, and A. Camps are with the Remote Sensing Laboratory, Department of Signal Theory and Communications, Universitat Politècnica de Catalunya, Barcelona E-08034, Spain, with the Institut d'Estudis Espacials de Catalunya, Barcelona E-08034 Spain, and also with the Barcelona Expert Centre, Barcelona E-08003, Spain (e-mail: david.chaparro@tsc.upc.edu; merce@tsc.upc.edu; camps@tsc.upc.edu).

J. Vayreda, M. Banqué, and J. Martínez-Vilalta are with the Centre for Ecological Research and Forestry Applications, Barcelona 08034, and also with the Universitat Autònoma de Barcelona, Barcelona 08034, Spain (e-mail: j.vayreda@creaf.uab.cat; m.banque@creaf.uab.cat; jordi.martinez.vilalta@ uab.cat).

M. Piles is with the Barcelona Expert Centre, Barcelona E-08003, Spain, and also with the Institut de Ciències del Mar-Consejo Superior de Investigaciones Científicas, Barcelona E-08003, Spain (e-mail: maria.piles@tsc.upc.edu).

This paper has supplementary downloadable multimedia material available at http://ieeexplore.ieee.org provided by the authors. The supplementary file contains a file containing additional text, seven supplementary tables, and one supplementary figure. The total size of the file is $3.72 \mathrm{MB}$.

Color versions of one or more of the figures in this paper are available online at http://ieeexplore.ieee.org.

Digital Object Identifier 10.1109/JSTARS.2016.2585505
Index Terms-Climate change, drought, forest decline, forest monitoring, predictive modelling, regional scale, soil moisture, soil moisture and ocean salinity (SMOS), temperature anomalies.

\section{INTRODUCTION}

O LOBAL change is putting forests under pressure, mostly due to changes in climate and land use [1]. Droughts and high-temperatures reduce soil water availability and increase evaporative demand, and have been associated with widespread events of drought-induced mortality in forests even in environments not considered to be water limited [2]-[4]. Climatic changes, together with disturbances directly related to human activities, are putting many forests outside the ranges of conditions under which they developed and may be too fast for evolutionary adaptation processes to keep pace [5]. Forest decline events are generally defined as episodes with increased mortality and crown defoliation rates, which can have dramatic effects on forest ecosystem services and have the potential to modify climate regulation and biogeochemical cycles at local and regional scales [6]. Forest mortality events are predicted to increase as a result of climate change, especially in areas where the climate is expected to become hotter and drier, such as the Mediterranean basin [7].

A growing number of forest decline events are being documented worldwide [2]. However, the number of studies showing consistent increases in leaf loss or mortality over substantial (e.g., decadal) time scales (e.g., [8]) is still scarce. Moreover, knowledge of the determinants of the spatial variability in forest mortality is still limited. Most studies have focused on relatively small spatial scales, showing that mortality frequently affects preferentially larger trees [9] and tends to be associated with high tree density (and thus competition; [10]) and shallow soils (e.g., [11]). At larger scales, the few available studies tend to use the databases assembled for national forest inventories [12]-[14]. However, the applicability of large-scale forest inventories to tree mortality research suffers from important limitations, including low temporal resolution (typically $\sim 10$ years) and low number of trees sampled per plot, which limits the capability to detect and quantify relatively random and usually infrequent events [15].

The lack of programs monitoring forest dieback at regional to global scales using standardized protocols and surveying exhaustively all forested lands greatly limits the capacity to draw strong conclusions on the vulnerability of different forest types or different areas within the distribution of a given species [2], [4], [5]. Due to the practical impossibility of surveying all forested lands at large geographical scales, ground-based 
surveys will necessarily need to be complemented by remote sensing techniques [16].

Spatially explicit studies of forest decline have taken advantage of available databases, including meteorological data from networks of weather stations and detailed topographical data (digital elevation models). However, water availability to plants depends critically on soil water content and on the physical properties of soil. In November 2009, the European Space Agency launched the Soil Moisture and Ocean Salinity (SMOS) mission [17]. This new satellite mission carries the payload MIRAS (Microwave Imaging Radiometer using Aperture Synthesis; [18]), the first space borne interferometric radiometer at L-band. Over land, SMOS-derived global soil moisture maps are obtained every three days at $\sim 40-\mathrm{km}$ spatial resolution (L2 product) and improved to $\sim 25 \mathrm{~km}$ (L3 product; [19]). L2 products have been extensively validated [20]-[22]. However, the spatial resolution of the observations is too coarse to serve local or regional applications, where higher spatial resolutions are needed. In order to fill this gap, downscaling or data disaggregation is becoming a recognized modeling framework to improve the spatial resolution of available surface soil moisture satellite products [23], and a number of studies have emerged with different approaches [23]-[32]. The algorithm used (see [30]) combines SMOS data with Land Surface Temperature (LST) and Normalized Difference Vegetation Index (NDVI), both estimated with moderate resolution imaging spectroradiometer (MODIS; see [33]), in order to obtain finer scale $(1 \mathrm{~km})$ soil moisture maps (L4 product; [19]). They are operationally provided by the Barcelona Expert Center (BEC) (see [34]).

Our study takes advantage of a regional program monitoring forest decline events in Catalonia (Northeastern Spain), which started in 2010 and has registered 527 events affecting a total area of $400 \mathrm{~km}^{2}$ (DEBOSCAT project; [35]). The DEBOSCAT survey registers areas $>0.03 \mathrm{~km}^{2}$ in which trees are affected by mortality, or leaf loss, or discoloration. Catalonia has several features that make it particularly suitable to study the spatial determinants of forest decline: 1) droughts are common in the region and most of its forests are considered to be limited by water; 2) its predominant Mediterranean climate determines high spatiotemporal variability in temperature and rainfall, which causes particularly severe and spatially complex drought events; 3 ) the orography and climate of Catalonia are extremely variable for the size of the region $\left(\sim 32000 \mathrm{~km}^{2}\right)$ (see Section II-A); and 4) Catalonia is at the boundary between Mediterranean and Euro-Siberian biogeographic regions, which determines that several species reach their Southern (and dry) distribution limit in the area. Previous studies suggest that these species may be particularly vulnerable to increase in drought stress in the study area (e.g., [36] for Pinus sylvestris, or [37] for Fagus sylvatica).

Our main objectives here are to use the DEBOSCAT database together with GIS tools, climatic, and remote sensing soil moisture data (i.e., SMOS-derived data) to determine the main environmental drivers of recent forest decline in Catalonia in terms of climate, drought characteristics, and soil water availability; and to establish the vulnerability to drought-induced decline of the main tree species in Catalonia. We hypothesize

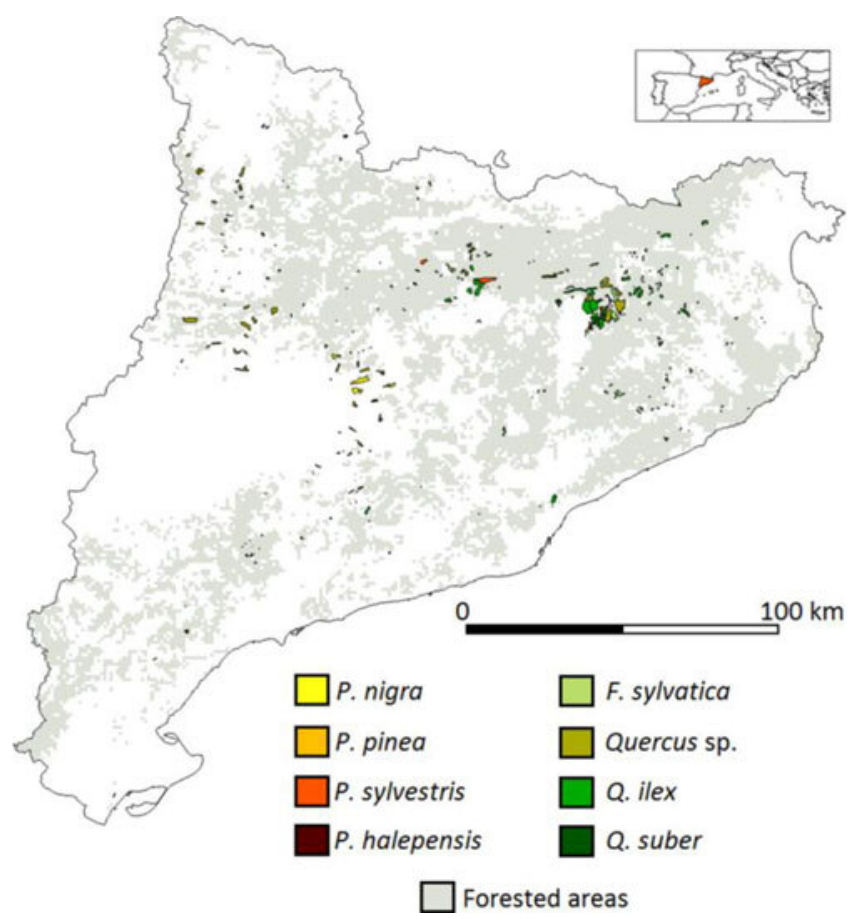

Fig. 1. Affected and unaffected areas and species. Map of Catalonia showing the location $(1 \mathrm{~km} \times 1 \mathrm{~km}$ resolution) of forests affected or unaffected by 2012 decline events. Colors represent the dominant species within each episode. Topright corner map shows the location of Catalonia in Southern Europe.

that 1) forest decline will affect preferentially areas with high-temperature anomalies, high drought intensity, and low soil moisture; 2) climatically drier sites will not necessarily be more vulnerable to drought-induced forest decline, due to the greater drought resistance of the dominant vegetation in these areas; and 3) Euro-Siberian species reaching their southern distribution limit in the Iberian Peninsula (particularly F. sylvatica and $P$. sylvestris) will be more vulnerable than typically Mediterranean species (i.e., Quercus ilex, Quercus suber, or Pinus halepensis).

\section{MATERIALS AND MethodS}

\section{A. Study Area}

We studied the forested area of Catalonia, in Northeastern Spain $\left(42^{\circ} 51^{\prime} \mathrm{N}-40^{\circ} 31^{\prime} \mathrm{N}, 0^{\circ} 9^{\prime} \mathrm{E}-3^{\circ} 19^{\prime} \mathrm{E}\right.$; Fig. 1$)$. Most of the study area has a typical Mediterranean climate, with mild winters and hot dry summers, with an irregular pattern of precipitation among years. Mean annual rainfall ranges from 336 to 1464 $\mathrm{mm}$ and mean annual temperature from 0 to $17.3{ }^{\circ} \mathrm{C}$ (see Fig. 2(a) and (b); [38]). Different relief units influence climate and vegetation. Colder and wetter conditions are found in the Pyrenees mountain ranges (up to $3150 \mathrm{~m}$ ), in the north of the region. Much drier climates occur along the coast, and, particularly, in the central depression, where rainfall is $<500 \mathrm{~mm} / \mathrm{year}$, and there is a noticeable continental influence (see Fig. 2(a) and (b)). Otherwise, coastal ranges (up to $1700 \mathrm{~m}$ ) present mild temperatures due to maritime influence, although conditions vary depending on elevation and distance to the coast. 


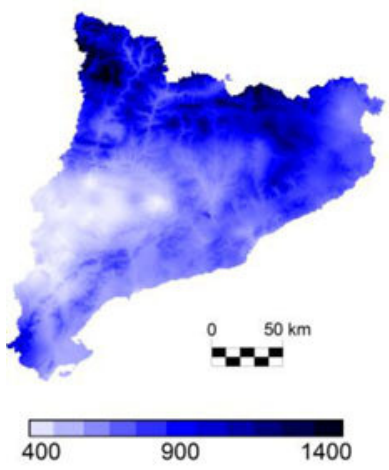

(a)

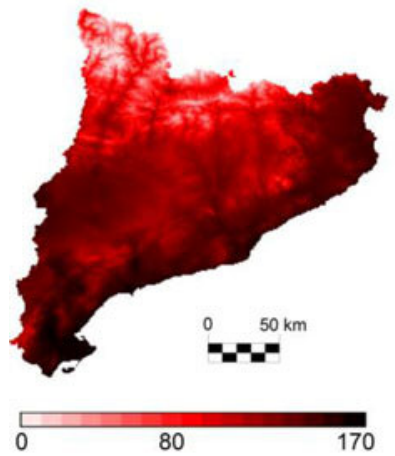

(c)

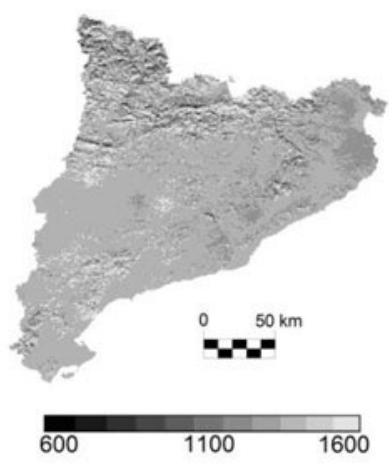

(b)

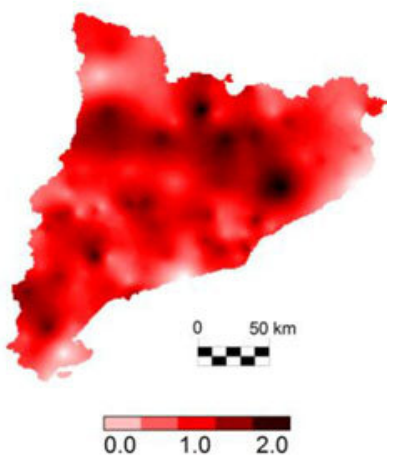

(d)
Fig. 2. (a) Mean annual accumulated precipitation $(\mathrm{mm})$ in Catalonia for the period 1950-1998; (b) mean annual temperature $\left({ }^{\circ} \mathrm{C}\right)$ for the period 1950 1998; (c) mean daily solar radiation $\left(10 \mathrm{~kJ} \cdot \mathrm{m}^{-2} \cdot \mathrm{day}^{-1}\right)$; (d) summer temperature anomaly $\left({ }^{\circ} \mathrm{C}\right.$ ) in summer 2012. Data for panels (a)-(c) were obtained from the Climatic Digital Atlas of Catalonia [38]. Data for panel (d) was obtained from the Catalan Meteorological Service (SMC).

Severe drought events are common in the study area. The most recent one was registered in summer 2012, which was preceded by the period October 2004-October 2008, the driest and longest drought event registered in the last 100 years in Northeastern Spain [39]. Although it was not as severe as this preceding period, the drought registered in 2012 was also important, especially in winter, when the accumulated precipitation was $70 \%-100 \%$ lower than the climatic mean (i.e., less than $25 \mathrm{~mm}$ in the west areas of the country) [40]. The spatial distribution of precipitation during spring was irregular with north and central areas above the mean $(+10 \%$ to $+100 \%)$ and northeast, west, and south areas being drier (10\% to $70 \%$ lower than the climatic average) [40]. During summer, the accumulated precipitation registered values between $-30 \%$ to $-100 \%$ below the mean in almost all Catalonia, particularly in northeastern regions [40]. Temperature and rainfall anomalies (the latter measured using the standardized precipitation index (SPI)) for summer 2012 are given in Figs. 2(d) and 3(a), respectively. Mean summer temperature anomaly was $+1.6{ }^{\circ} \mathrm{C}$ for 2012 and it was positive throughout the study area (see Fig. 2(d)).

Catalan forests occupy more than $13000 \mathrm{~km}^{2}$ (nearly $40 \%$ of the territory). The most widely distributed species are $\mathrm{Pi}$ nus halepensis $\left(2430 \mathrm{~km}^{2}\right)$ and Quercus ilex $\left(2000 \mathrm{~km}^{2}\right)$ [41]. Both are Mediterranean species typically coexisting in coastal forests, although Quercus ilex has a wider altitudinal range. $P i$ - nus sylvestris (covering $1970 \mathrm{~km}^{2}$ ) is a Euro-Siberian species living close to its Southern distribution limit and dominating forests between 1000 and $1800 \mathrm{~m}$ [42]. Other Euro-Siberian species living near their Southern distribution limits are $\mathrm{Fa}$ gus sylvatica and Pinus uncinata, occupying forests between 1400 and $2200 \mathrm{~m}$. Pinus nigra $\left(1070 \mathrm{~km}^{2}\right)$ grows mostly in the pre-Pyrenees and Catalan inlands. Deciduous oaks are also abundant, mainly Quercus pubescens $\left(820 \mathrm{~km}^{2}\right)$ and Quercus faginea $\left(325 \mathrm{~km}^{2}\right)$ [41], [42].

\section{B. Forest Condition Database (DEBOSCAT)}

DEBOSCAT is a monitoring program started in 2010 to assess health condition in all the forests in Catalonia. The project is coordinated by the Centre for Ecological Research and Forestry Applications (CREAF, Barcelona, Spain). All the forests in Catalonia are surveyed annually (in September) by forest rangers deployed by the Catalan Government in order to detect forest decline events after summer. Forest decline events are defined as areas $>0.03 \mathrm{~km}^{2}$ in which tree mortality is higher than $5 \%$ or the sum of leaf loss plus discoloration exceeds $50 \%$ in the canopies of at least one abundant tree species (with $>15 \%$ canopy cover). Each event is identified by a unique code, and the recorded information includes: 1) exact geographical location and perimeter of the affected area, 2) the abundance of the dominant species (in terms of canopy coverage), and 3) the percent of crowns affected and the type of damage (mortality, discoloration, or leaf loss) for each species. All the registered events are transferred to a GIS layout with its corresponding database [35]. Validations conducted by an independent team showed good agreement between different observers, as the percentage of estimated nondamaged trees [i.e., $100-(\%$ mortality $+\%$ discoloration $+\%$ leaf loss $)]$ was within $10 \%$ of the initially estimated value in $81 \%$ of cases ( $N=20$ resampled events; $\mathrm{M}$. Banqué, unpublished results).

In this study, we only used the recent events detected in 2012, as the 2010 and 2011 surveys were preliminary and were used here only to determine which events corresponded to new 2012 occurrences. DEBOSCAT registered more than $230 \mathrm{~km}^{2}$ newly affected in 2012, distributed in 340 events (see Table I; [43]) which are shown in Fig. 1. Each event could contain more than one affected species, but we only retained combinations of events by species for which mortality was $\geq 5 \%$ or (discoloration + leaf loss) occurred in $\geq 25 \%$ of the canopies to ensure that affectation was high in all instances (note that not all species within an event fulfilled the $50 \%$ criteria stated in the previous paragraph). Only $11.8 \%$ of the combinations of events by species in the database had a percentage of discoloration + leaf loss between $25 \%$ and $50 \%$. We focused on the most affected species and merged all deciduous oaks into one single category (deciduous Quercus, including basically $Q$. pubescens and $Q$. faginea) due to the high morphological and ecophyisiological similarity of the species and due to the fact that they frequently hybridize in the study area [44]. Hence, the studied species were deciduous Quercus, Quercus ilex, Quercus suber, Fagus sylvatica, Pinus sylvestris, Pinus nigra, Pinus halepensis, and Pinus pinea. These species dominate $75 \%$ of the forests in Catalonia 
TABLE I

DECLINE EVENTS ON 2012

\begin{tabular}{lccccc}
\hline \hline Species & Events & $\begin{array}{c}\text { Affected area } \\
\left(\mathrm{km}^{2}\right)\end{array}$ & $\%$ affected & $\begin{array}{c}\text { Occupied area } \\
\left(\mathrm{km}^{2}\right)\end{array}$ & $\%$ \\
\hline Dec. Quercus & 219 & 100.1 & 42.39 & 1260.76 & 7.94 \\
F. sylvatica & 36 & 19.29 & 8.17 & 336.11 & 5.74 \\
Q. ilex & 205 & 82.02 & 34.74 & 2003.5 & 4.09 \\
Q. suber & 26 & 5.38 & 2.28 & 608.32 & 0.88 \\
Broadleaved & $\mathbf{4 8 6}$ & $\mathbf{2 0 6 . 7 9}$ & $\mathbf{8 7 . 5 8}$ & $\mathbf{4 2 0 8 . 6 9}$ & $\mathbf{4 . 9 1}$ \\
species & & & & & \\
P. nigra & 39 & 9.87 & 4.18 & 1070.44 & 0.92 \\
P. sylvestris & 42 & 8.05 & 3.41 & 1965.43 & 0.41 \\
$P$. pinea & 18 & 0.9 & 0.38 & 332.25 & 0.27 \\
P. halepensis & 38 & 4.51 & 1.91 & 2429.54 & 0.19 \\
Conifers & $\mathbf{1 3 7}$ & $\mathbf{2 3 . 3 3}$ & $\mathbf{9 . 8 8}$ & $\mathbf{5 7 9 7 . 6 6}$ & $\mathbf{0 . 4}$ \\
Other species & 66 & 6 & 2.54 & 1397.43 & 0.19 \\
Total & $\mathbf{3 4 0}$ & $\mathbf{2 3 6 . 1 2}$ & $\mathbf{1 0 0}$ & $\mathbf{1 1 4 0 3 . 7 8}$ & $\mathbf{2 . 0 4}$ \\
\hline \hline
\end{tabular}

Decline events detected in 2012 by species in terms of number of events, affected area, percentage in relation to total affected area, total area occupied by each species, and percentage of the total area occupied that was affected in 2012. Data about decline events were obtained from the DEBOSCAT project (Banqué et al. [43]), and species distribution areas were obtained from the Land Cover Map of Catalonia (CREAF and Generalitat de Catalunya [41]). * Total of events is lower than the addition of events for each species because one event might contain more than one species. We finally worked with a total of 288 events (the remaining 52 were not considered because they affected species that were not included in this study or the magnitude of the reported damage did not fulfil our criteria).

and represent $99 \%$ of the events detected in 2012. Our final database contained a total of 288 from the original 340 events (see Table I; Fig. 1) when all the episodes fulfilling the mentioned criteria were chosen. Table $\mathrm{S} 1$ shows that the percentage of events affected by mortality varied widely among species. For deciduous species (deciduous Quercus and Fagus), the timing of DEBOSCAT field surveys (early September) ensured that the events reported did not overlap with autumn leaf shedding (starting late October in the study region).

In order to compare affected events with unaffected areas, we used the Land Cover Map of Catalonia [41] to create a $1 \mathrm{~km} \times 1 \mathrm{~km}$ grid covering its whole forested area. Each cell in the grid was assigned to the modal species of the Land Cover Map. Grid cells were classified as affected, if at least $10 \%$ of its surface overlapped with a polygon affected by forest decline, or unaffected, if there were no events overlapping the corresponding cell, or they covered $<10 \%$ of the cell's surface. In the few cases in which an event did not cover more than $10 \%$ of the surface of any cell, the event was assigned to the most affected cell. To assess the impact of this $10 \%$ threshold on our results, we repeated the analyses using higher threshold levels $(20 \%$, $30 \%, 40 \%$, and $50 \%$ ) and confirmed that they did not change our main results (data not shown).

\section{Additional Environmental Databases}

Several explanatory variables were used to model the distribution of decline events in summer 2012, including lithology, historical climate characteristics, and specific climatic conditions and soil moisture during summer 2012, which were obtained as follows:

Lithology was obtained from the geological map of Catalonia [45] and reclassified in two categories: basic (calcareous)

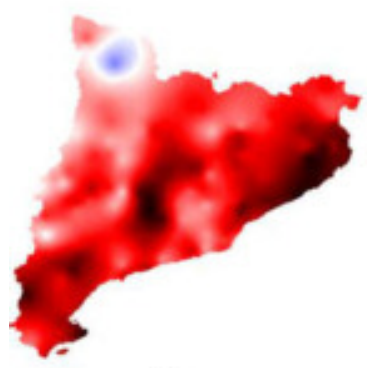

(a)

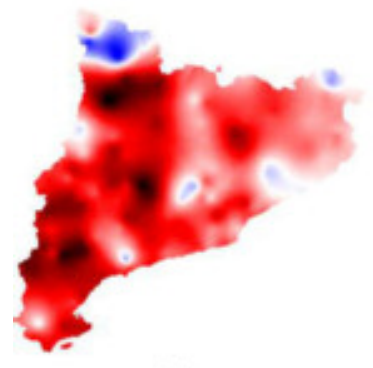

(c)

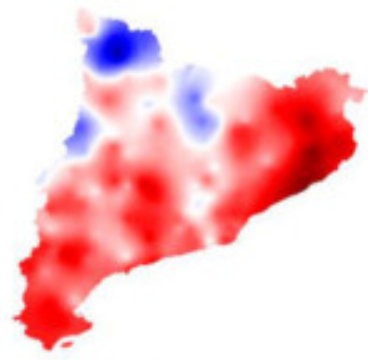

(b)

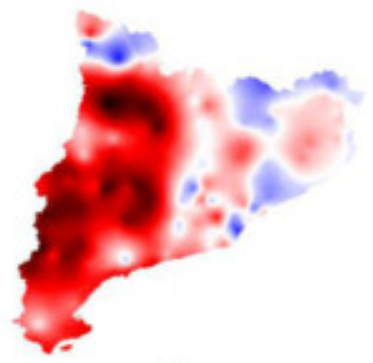

(d)

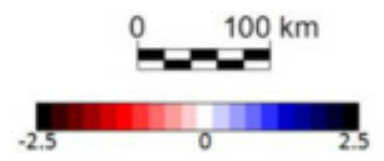

Fig. 3. SPI in Catalonia calculated for different time periods: (a) June-August 2012 (SPI3); (b) March-August 2012 (SPI6); (c) September 2011-August 2012 (SPI12); and (d) September 2010-August 2012 (SPI24). SPI is a dimensionless variable. Positive values indicate precipitation above the mean and negative values indicate precipitation below the mean. The mean was calculated for the period 1961-2013. Obtained and adapted from: Catalan Meteorological Service (SMC), 2013.

and acidic (siliceous) soils. Historical climate data were used to characterize "long-term," average conditions, and were obtained from the Climatic Digital Atlas of Catalonia [38] for the period 1950-1998. This data included mean annual and summer (June to August) temperatures, mean accumulated annual and summer (June to August) precipitations, and mean annual solar radiation. We upscaled all variables from $180 \mathrm{~m} \times 180 \mathrm{~m}$ to the common $1 \mathrm{~km} \times 1 \mathrm{~km}$ resolution using a bilinear interpolation method.

The SPI was used to characterize drought intensity at different time scales. Essentially, the SPI for a given month is calculated as the difference between the mean precipitation for the previous $n$-months and the mean for a reference time period, divided by the standard deviation for that reference period [46]. We used SPI data provided by the Catalan Meteorological Service (SMC) for periods of three months (SPI3: June 2012-August 2012), six months (SPI6: March 2012-August 2012), 12 months (SPI12: September 2011-August 2012), and 24 months (SPI24: September 2010-August 2012) (see Fig. 3). The reference period corresponded to years 1961-1990. Map resolution was $1 \mathrm{~km} \times 1 \mathrm{~km}$. Negative values indicate drier conditions than the reference (extremely drier below -2) and positive values reflect wetter conditions (extremely wetter above +2 ) [46]. The 
temperature anomaly in summer $2012\left(\Delta T_{-}\right.$summer) was provided by $\mathrm{SMC}$ at $1 \mathrm{~km} \times 1 \mathrm{~km}$ spatial resolution, and was calculated as the difference between mean summer temperature in 2012 and mean summer temperature for the period 1961-1990.

Daily SMOS-derived soil moisture maps at 1-km spatial resolution (L4 product) over Catalonia for summer 2012 (June 2012August 2012) were obtained from the BEC (see [34]), which uses a downscaling algorithm to combine coarse-scale SMOS information $(\sim 40 \mathrm{~km})$ with MODIS/Aqua LST and NDVI, obtaining fine-scale soil moisture estimates at $1 \mathrm{~km}$ (see [27], [30] and Supplementary Text in this paper for further information). SMOS-derived soil moisture is representative of approximately the top $5 \mathrm{~cm}$ of the soil [17], although in situ measurements from 0 to $3 \mathrm{~cm}$ depth showed slightly better correlation with brightness temperatures than those obtained for the entire top $5 \mathrm{~cm}$ ([47] in SMOSREX experiment, Southern France) specially under wet soil conditions. SMOS operates at L-band (1.4 $\mathrm{GHz}$ ), the optimal frequency for retrieving soil moisture information, which can be estimated in areas where the overall vegetation water content of the studied pixels is $<5 \mathrm{~kg} / \mathrm{m}^{2}$. This condition only excludes areas with a nearly homogeneous cover of highly dense forests, such as jungles or taiga [48], [49], which is not the case of Catalonia. Still, the presence of dense vegetation has an impact in the accuracy of L-band soil moisture estimates; validation of SMOS-derived soil moisture under forested covers has been carried out in [21] (at $\sim 40-\mathrm{km}$ resolution), and in [30] (at 1-km resolution), showing that retrieval under forested areas is less accurate than for other vegetation types.

For this study, the mean summer soil moisture over Catalonia was obtained using SMOS afternoon passes (Fig. 4), since validation studies over the Iberian Peninsula have revealed better correlations with in situ data for afternoon than for morning passes [30], [31]. Mean values show the extremely dry conditions of the soil during summer 2012, with moisture values ranging from 0.08 to $0.14 \mathrm{~m}^{3} \cdot \mathrm{m}^{-3}$. Although this range is narrow and near to $0.04 \mathrm{~m}^{3} \cdot \mathrm{m}^{-3}$ (the SMOS-derived soil moisture product expected accuracy), this is largely due to the fact that data were averaged for a period of three months. Daily ranges of SMOS-derived soil moisture were wider than $0.04 \mathrm{~m}^{3} \cdot \mathrm{m}^{-3}$ for more than $90 \%$ of the days, and at least twice the expected accuracy for more than $60 \%$ of the days. See Supplementary Text for additional information about SMOS datasets.

\section{Statistical Methods}

Forest decline probability for each species was modeled as a function of lithology, climate characteristics, specific climatic conditions in summer 2012, and SMOS-derived soil moisture, using logistic regression models. We used Pearson's correlation coefficients $(r)$ to detect redundancy among the explanatory variables (Table S2). Whenever a pair of variables had a correlation $r>0.51$, we selected the one resulting in a better model fit in terms of the Akaike Information Criterion (AIC) and rejected the other one, to avoid multicollinearity. The final set of explanatory variables was composed by species (Table S3), mean annual radiation (see Fig. 2(c)), mean annual pre-

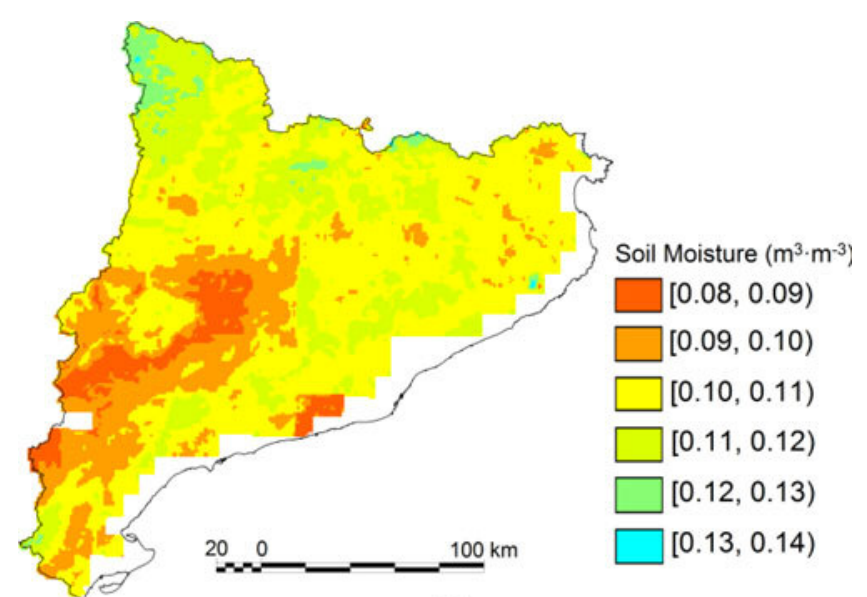

(a)

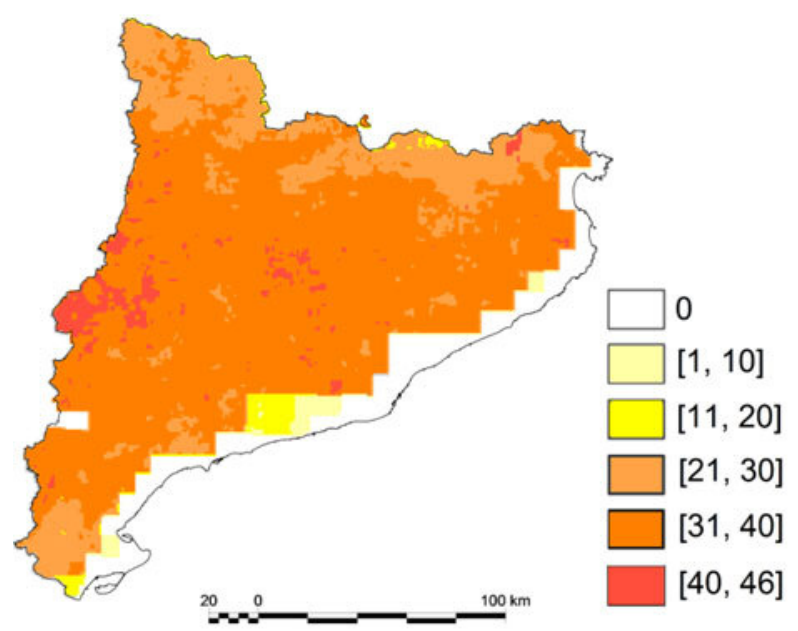

(b)

Fig. 4. Mean soil moisture. (a) Mean soil moisture during summer 2012 in Catalonia, as estimated by the SMOS platform (SMOS afternoon passes; units: $\mathrm{m}^{3} \cdot \mathrm{m}^{-3}$ ). Coastal areas are not represented due to inexact transition between SMOS measures; (b) number of days in summer with soil moisture (SMOS) data available per pixel. No data are obtained in coastal areas due to inexact transition between SMOS measures.

cipitation (see Fig. 2(a)), summer 2012 temperature anomaly (see Fig. 2(d)), SPI3, SPI12 (see Fig. 3(a), (c), respectively), and mean summer soil moisture (see Fig. 4(a)). All the quantitative predictors were centered and standardized at a global level before fitting the models. As our main focus was on the effects of the specific environmental conditions during summer 2012, we also introduced the interactions between species and summer 2012 temperature anomaly, SPI3, SPI12, and soil moisture. Additional models including the interactions of radiation and precipitation with species were considered during model selection but did not improve model fit significantly and these interactions were removed in our final analyses. Similarly, preliminary models showed that the effect of lithology was never significant and this variable was not included in the final models.

To avoid a highly unbalanced sample due to the higher number of unaffected entries in our dataset, we used only a random 
subset of unaffected entries corresponding to twice the number of affected ones (see Table S3). This random resampling was done globally, and not per species, because we were interested in the general capacity of the model to explain decline occurrence in the study area (with its current distribution of different forest types) and not necessarily in capturing the true decline probabilities by species. Although modeled decline probabilities do not necessarily represent the species' absolute decline probabilities, the relative probabilities across species are conserved (see [50]). The random selection was repeated ten times to ensure that our main results were robust to this selection (see Table S4). The residuals of our final model showed only moderate spatial structure at small spatial scales (below $20 \mathrm{~km}$ ). We used the variance inflation factors (VIF) for the model variables to quantify the severity of multicollinearity. VIF was $>5$ only for SPI3 (VIF $=6.48$ ). To explore the potential effect of multicollinearity in this study, we refitted our model without this variable. Results showed that remaining model coefficients were similar to those in the original model in terms of significance, sign, and magnitude (results not shown), implying that multicollinearity did not have a major influence in this case. In the final model, predicted probabilities of being affected were compared with the binary information from the observed dataset, and model performance was assessed using the area under the receiver operating characteristic curve (AUC). Significance for all statistical analyses was accepted at $p<0.05$. All models were fitted using the $\mathrm{R}$ software (v3.0.0, The R Foundation for Statistical Computing).

\section{RESULTS}

\section{A. Overview of Forest Decline Events Detected in 2012}

A total of 340 new events of forest decline were detected in September 2012 , affecting $236.12 \mathrm{~km}^{2}$, (2.1\% of total forested area in Catalonia). These events impacted mostly broadleaved species, both in absolute terms (number of events and area affected) and in relative terms (in relation to the overall distribution area of each species). The percentage of the species' distribution area affected ranged from $0.9 \%$ (Quercus suber) to $7.9 \%$ (deciduous Quercus) in broadleaved species, and between $0.2 \%$ (Pinus halepensis) and $0.9 \%$ (Pinus nigra) in conifers (see Table I). Deciduous Quercus forests accounted for $42 \%$ of all affected areas, Quercus ilex accounted for 35\%, and Fagus sylvatica for $8.2 \%$. Conifers were much less affected and, overall, accounted for only $10 \%$ of the impacted areas. In absolute terms, Pinus pinea, Pinus pinaster, and Pinus uncinata were the least affected species, whereas Pinus halepensis was the least affected in relative terms, as only $0.19 \%$ of its distribution area was damaged (see Table I).

The percentage of events affected by mortality varied widely among species, independently of the differences in the amount of decline between broadleaves and conifers. In particular, most species showed mortality in $>50 \%$ of the episodes during the preceding year, except for $P$. halepensis (34.1\%), Q. suber $(8.8 \%)$, and $F$. sylvatica, which was only affected by defoliation and/or discoloration (see Table S1). Finally, the amount of decline events increased two years later on most species (mainly on P. sylvestris), but decreased on deciduous Quercus and Fagus sylvatica (see Table S1).

\section{B. Determinants of Forest Decline}

Our models explained $36 \%-39 \%$ of the deviance in the decline probability, depending on the random selection of nonaffected cells (see Section II-D). AUC for the final model was 0.893 (AUC $>0.8$ indicates an excellent fit; [51]). All models gave very consistent results in terms of the values of the estimated coefficients and the significance of the effects (see Table S4) and the following results are based on the model with lowest AIC, which is the final model (39.3\% of explained deviance, Table S5). Not surprisingly, considering what has been reported in the previous section, the model identified species identity as the most influential factor explaining forest decline (see Table S6). The ranking of species damage predicted by the model followed closely the results reported in the previous section (see Fig. S1). Climatic radiation and precipitation had a positive effect on decline occurrence (see Table S5).

Regarding the variables characterizing the environmental conditions during year 2012, they all showed significant interactions with species (see Table S5). The effect of SPI3 and SPI12 on decline probability was consistently negative, but not always significant, for all species, except for $P$. sylvestris. The negative effect of SPI3 on decline occurrence was significant for Pinus halepensis, Pinus nigra, and Fagus sylvatica (see Fig. 5 and Table S5), whereas SPI12 presented significant negative effects for Pinus nigra, Quercus suber, Quercus ilex, and Fagus sylvatica (see Fig. 6 and Table S5). Thus, lower rainfall was associated with higher decline. Summer temperature anomaly ( $\Delta T \_$summer) increased decline probability in most species and had strong and significant effects on all species except $P$. nigra, $P$. pinea, and P. halepensis (see Fig. 7 and Table S5). Finally, low values of estimated soil moisture increased the probability of forest decline in all species, although the effects were only significant for deciduous Quercus, Q. ilex, F. sylvatica, P. nigra, and P. sylvestris (see Table S5 and Fig. 8).

\section{DISCUSSION}

\section{A. Local Climatic Anomalies as Determinants of Drought Effects on Different Forest Species}

Our results showed a remarkable coherence in the effects of the variables describing climate anomalies and soil moisture distribution. In general, an area was more likely to be affected wherever temperatures were particularly high and rainfall particularly low during summer 2012, compared to long-term averages, resulting in low water content in surface soils. Interestingly, the effects of rainfall at the summer and whole-year timescales were spatially independent from each other, suggesting that rainfall accumulated at these different timescales might need to be accounted for separately in models of drought effects on forests [52]. The positive relationship between temperature anomaly and decline occurrence observed in our study is consistent with recent reports highlighting the key role of high temperatures and vapor pressure deficit in drought-induced forest mortality 


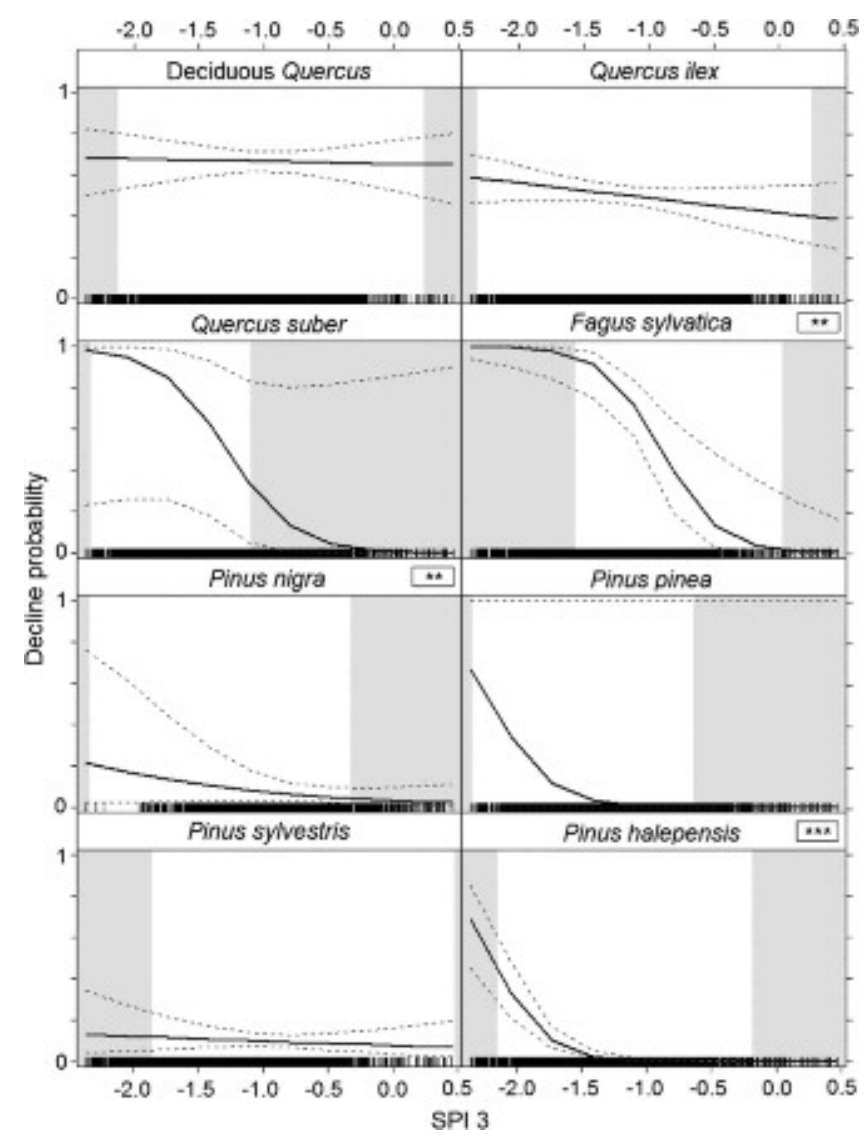

Fig. 5. Effect of SPI3 on decline probability. Modeled effect of the SPI on a three month timescale (SPI3) on decline probability for each of the studied species. SPI3 is dimensionless. Values of SPI3 were back-transformed to the original scale for display purposes. Black curves show effects and dashed lines show $95 \%$ confidence intervals. As minimum and maximum SPI3 values are different for each species, shaded rectangles show SPI3 values out of the range for each species, where effects are extrapolated. Top-right boxes show the significance of the effects for a given species, as $p<0.05(*), p<0.01(* *)$, and $\mathrm{p}<0.001(* * *)$. A rug plot is shown giving the marginal distribution of the predictor on the horizontal axis.

[53]. Similarly, our results are in agreement with the studies highlighting soil moisture as an important factor explaining the spatial distribution of forest decline. For instance, in [54] it is shown that low shallow $(<10 \mathrm{~cm})$ soil moisture was associated to the spatial patterns of sudden aspen (Populus tremuloides) decline in Western USA. It should be noted, however, that the study species are likely to extract most water from deeper soil layers than those sensed by SMOS, and the relationship between SMOS-derived shallow soil moisture and soil water availability to plants requires further investigation.

Our results showed that forests growing in sites under wetter mean climatic conditions and in areas more exposed to radiation were more likely to experience decline. Recent studies have shown that the vulnerability to drought may remain approximately constant across biomes [55], and that even species from very humid locations (e.g., tropical rainforests) are prone to suffer from drought [56]. Similarly, populations from drier areas may be better adapted to drought, resulting in a similar or

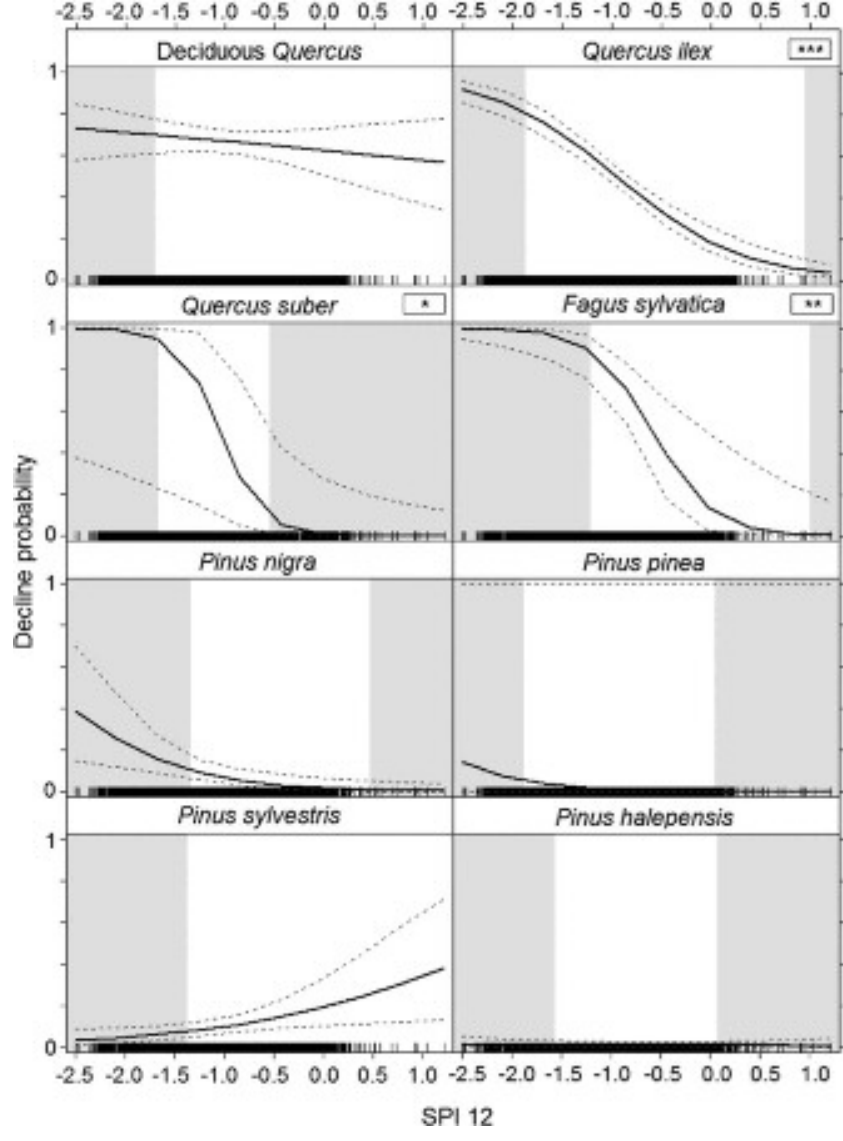

Fig. 6. Effect of SPI12 on decline probability. Modeled effect of the SPI on a yearly timescale (SPI12) on decline probability for each of the studied species. SPI12 is dimensionless. Values of SPI12 were back-transformed to the original scale for display purposes. Black curves show effects and dashed lines show 95\% confidence intervals. As minimum and maximum SPI12 values are different for each species, shaded rectangles show SPI12 values out of the range for each species, where effects are extrapolated. Top-right boxes show the significance of the effects for a given species, as $p<0.05(*), p<0.01(* *)$, and $p<0.001$ $(* * *)$. A rug plot is shown giving the marginal distribution of the predictor on the horizontal axis.

higher vulnerability in wetter areas even within the range of a given species (e.g., [57]).

\section{B. Broadleaved Trees Were More Affected by the 2012 Drought Than Conifers}

Consistent with the higher susceptibility of broadleaved species, they tended to be more sensitive to the studied drivers of drought stress than conifers. This result agrees with the fact that conifers have wider safety margins from hydraulic failure in their xylem, both in general [55] and also in particular for the set of species studied here (see Table S7). However, drought resistance in plants is complex and multifaceted, and vulnerability to xylem embolism is by no means its only component, nor the only one differing between angiosperms and gymnosperms [58]. Generally, broadleaved species tend to have deeper roots, and all the broadleaves included in this study are able to resprout, whereas the studied conifers are not. These differences might explain why the higher damage of broadleaves observed 


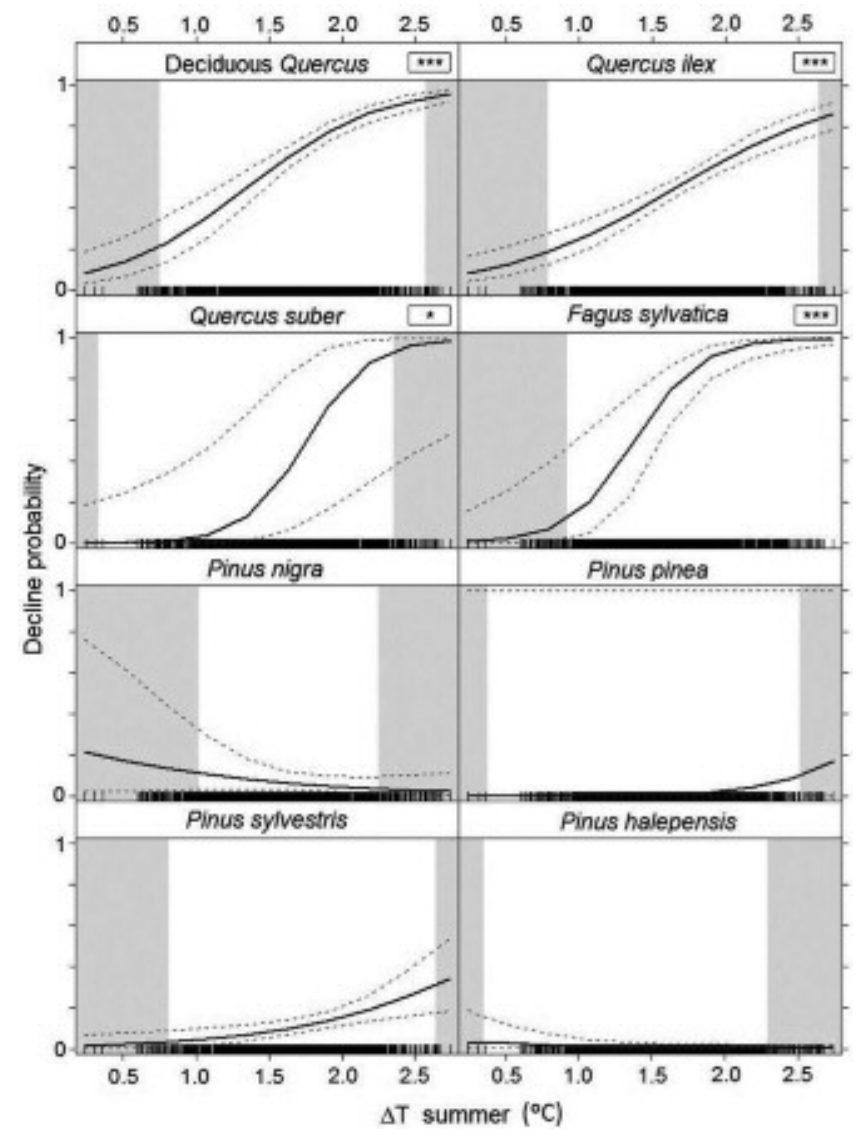

Fig. 7. Effect of anomaly of temperature on decline probability. Modeled effect of the summer 2012 temperature anomaly $\left(\Delta T_{-}\right.$summer, in $\left.{ }^{\circ} \mathrm{C}\right)$ on decline probability for each of the studied species. Values of $\Delta T \_$summer were back-transformed to the original scale for display purposes. Black curves show effects and dashed lines show 95\% confidence intervals. As minimum and maximum $\Delta T_{-}$summer values are different for each species, shaded rectangles show $\Delta T_{-}$summer values out of the range for each species, where effects are extrapolated. Top-right boxes show the effect significance as $p<0.05(*), p<0.01$ $(* *)$, and $p<0.001(* * *)$. A rug plot is shown giving the marginal distribution of the predictor on the horizontal axis.

in summer 2012 was not observed in the previous DEBOSCAT surveys conducted in years 2010 and 2011 [35]. In 2013, a wet year in the study area, only 37 new decline events were recorded in the DEBOSCAT survey. Interestingly, however, the two species with higher area affected by new 2013 events were pines ( $P$. halepensis and $P$. sylvestris) [59]. In addition, several decline events registered during 2012 were recovered two years later in most broadleaved species, showing that the postdrought dynamics of the studied episodes should be a matter of study. In contrast, the increased number of decline events mainly in conifers on 2014 suggests that they may be more prone to suffer lagged mortality effects (e.g., [60] for P. sylvestris in the same study region, consistent with results shown in Table $\mathrm{S} 1$ for this species). Also, these results suggest that the differential vulnerability to drought of broadleaves and conifers might depend on the temporal development of drought and can vary from year to year even within a given location, perhaps providing an effective resilience mechanism over larger spatial and temporal scales (cf., [61]).

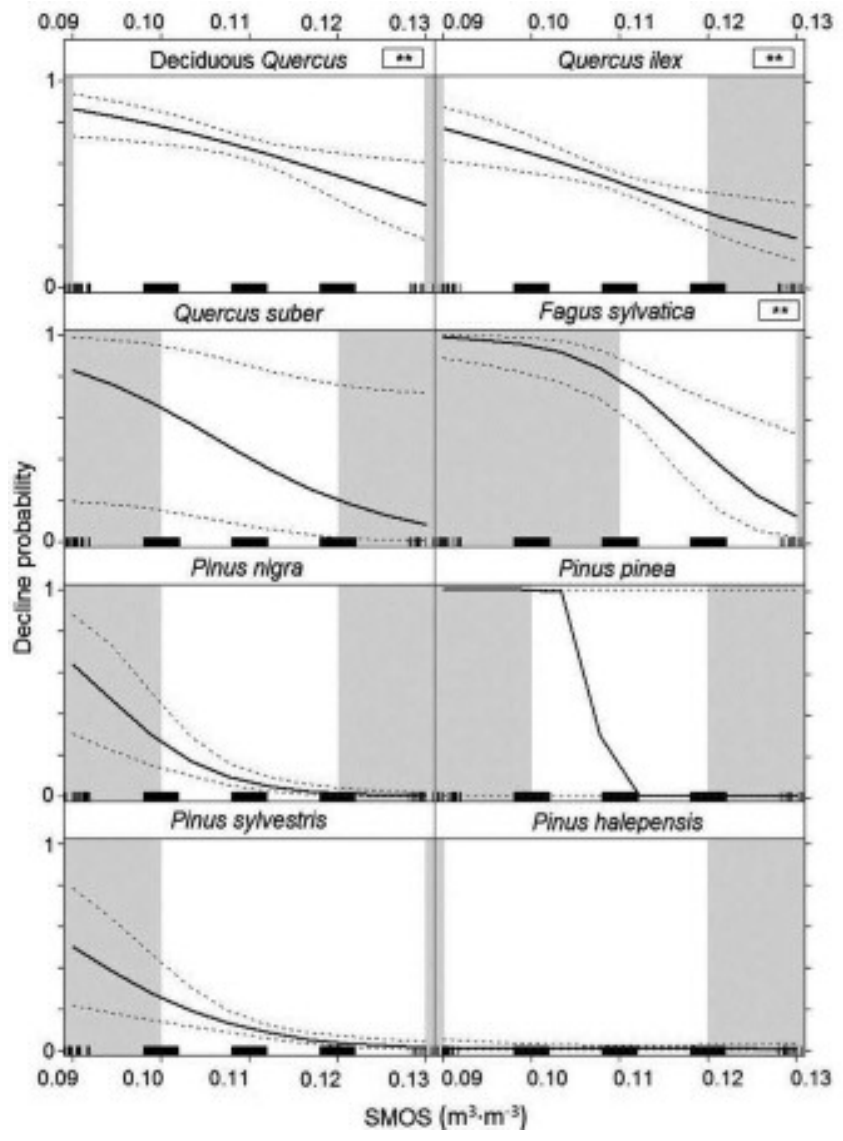

Fig. 8. Effect of soil moisture on decline probability. Modeled effect of soil moisture (SMOS, in $\mathrm{m}^{3} \cdot \mathrm{m}^{-3}$ ) on decline probability for each of the studied species. Values of SMOS were back-transformed to the original scale for display purposes. Black curves show effects and dashed lines show 95\% confidence intervals. As minimum and maximum SMOS values are different for each species, shaded rectangles show SMOS values out of the range for each species, where modeled effects are extrapolated. Top-right boxes show the significance of the effects for a given species, as $p<0.05(*), p<0.01(* *)$, and $p<0.001$ $(* * *)$. A rug plot is shown giving the marginal distribution of the predictor on the horizontal axis.

\section{Are Euro-Siberian Species More Vulnerable Than Mediterranean Species?}

Our hypothesis that Euro-Siberian species at the Southern (and dry) limit of their distribution would be more vulnerable to drought was only partially verified. Although Fagus sylvatica, a typical central European species, was highly impacted by drought in 2012 and was the most sensitive species to the majority of studied variables, another Northern species, such as the mostly Boreal Pinus sylvestris, was much less impacted (in 2012) and this impact was poorly related to the studied drivers. This result for Pinus sylvestris contrasts with several decline events detected for this species in the study area [11], [36], [60], [62] and with the higher damage of the species reported on the 2010, 2011, 2013, and 2014 DEBOSCAT campaigns [35], [59]. For the 2012 effects studied here, the influence of the species' biogeographical range was clearly less important than the type of species (broadleaved compared to conifers). Some typical Mediterranean species, such as Quercus ilex and Quercus suber, were highly affected, while Pinus halepensis was not. The high 
sensitivity of Fagus sylvatica to the studied factors suggests that increasing temperatures and droughts could strongly affect this species in the study region [37] and elsewhere in Europe [63].

\section{Toward a Predictive Monitoring of Forest Vulnerability to Drought}

The fact that the species distribution and the climatic anomalies during the study year explained a substantial proportion of the spatial distribution of forest decline, and that climatic effects were largely consistent across species, offers a promising avenue in terms of predicting forest decline at large spatial scales using GIS and remote sensing data. All the variables included in our study are relatively easy to calculate or readily available at different temporal and spatial resolutions for many regions of the globe (e.g., see [64]). At the same time, however, we note that our model explained $\sim 40 \%$ of the spatial variability in forest decline, and this percentage would be probably lower if the model was used to predict future decline events. This fact suggests that major determinants of the decline process were not accounted for in our study. The effect of previous droughts (such those occurred between 2004 and 2008 in the study area), for instance, might represent an important predisposing factor partially explaining the spatial distribution of current decline events. Although no large-scale pest effects were detected in 2012 in the study area, the impact of biotic agents is likely to be locally important [65]. Patterns of tree death are often patchy at fine spatial scales across the synoptic drought-affected region, which suggests the need to include more detailed-scale factors in future editions of the DEBOSCAT survey. Actually, decline patterns depend on the combination of ecosite variability (e.g., soils or slope) and density-dependent processes (e.g., competition or insect outbreaks) [2]. Stand development and structural characteristics have been related to forest decline in many studies (e.g., [8], [13]). Disturbance legacies, including past forest management practices, are the main determinants of current stand characteristics over most of the study region [13], [14], and may explain the clustering of decline episodes in some areas (see Fig. 1). Finally, fine scale soil characteristics such as texture or vertical development are also obvious contributors to forest decline occurrence [11], as root development is limited on shallow and/or rocky soils, obviously influencing water retention and availability independently of direct climatic effects.

Highly resolved soil moisture data obtained from remote sensing, such as the SMOS-derived dataset used in this study, offers a path forward for the predictive modeling of drought effects. The major limitation of SMOS downscaled data at present is the shallow soil depths at which SMOS is sensitive to $(0-5 \mathrm{~cm})$ [27], as it only captures a small fraction of the rooting zone of most tree species [66]. This drawback may explain the relatively low explanatory power of soil moisture in our study. This issue could be improved using surface moisture models (e.g., those from the Global Land Data Assimilation System [67]), or by estimating water content in deeper layers from surface soil moisture, e.g., adapting the methodology proposed by [68] to SMOS-derived data. Concerning its spatial resolution, the downscaled product is applicable to regional studies (while the L2 product is not) but a better resolution would be desirable and is under study [31]. Hence, soil moisture remote sensing data applicability and the possibility of improving its characteristics makes SMOS-derived data a promising tool with many potential applications in Earth sciences in general and forest ecology in particular.

\section{CONCLuSION}

We were able to explain a substantial proportion $(\sim 40 \%)$ of the spatial distribution of forest decline during the extremely dry summer of 2012 in Catalonia, Northeastern Spain, using widely available environmental data. We concluded that precipitation anomaly at different time scales, anomalies of temperatures, and surface soil moisture, were important and complementary to explain forest decline patterns. These results are promising because they show that predicting forest decline is possible. At the same time, however, the substantial proportion of variance that could not be explained by our model indicates that other factors (e.g., soil properties, ecosite variability, stand structure and management history, or occurrence of previous droughts) are also likely to be important and need to be taken under consideration in future monitoring programs and decline models. In general, climatically wetter and more exposed forests were more vulnerable than those located in drier or more shaded areas. More affected forests were also characterized by high positive temperature anomalies, low rainfall accumulated for the whole summer and for the previous year, and by correspondingly low soil moisture in surface layers. However, species differed in their overall affectation and in their susceptibility to the studied drivers. Overall, broadleaved species were more affected than conifers. Interestingly, species at the southern limit of their distribution were not necessarily more sensitive to the studied explanatory variables, nor necessarily more affected (e.g., P. sylvestris) than species distributed over drier areas, at least in the short term. We expect further developments in GIS and in the spatial and temporal resolution of remote sensing data, including soil moisture, to increase the predictive power of similar applications in the future.

\section{ACKNOWLEDGMENT}

The authors would like to thank A. Rius and V. Altava, from Catalan Meteorological Service, who kindly provided SPI and temperature anomalies' maps. They would also like to thank C. Calvera and Catalan forest rangers who meticulously provided the necessary information contained in the DEBOSCAT databases.

\section{REFERENCES}

[1] G. B. Bonan, "Forests and climate change: Forcings, feedbacks, and the climate benefits of forests," Science, vol. 320, pp. 1444-1449, 2008.

[2] C. D. Allen et al., "A global overview of drought and heat-induced tree mortality reveals emerging climate change risks for forests," Forest Ecol. Manage., vol. 259, pp. 660-684, 2010.

[3] N. G. McDowell, D. J. Beerling, D. D. Breshears, R. A. Fisher, K. F. Raffa, and M. Stitt, "The interdependence of mechanisms underlying climatedriven vegetation mortality," Trends Ecol. Evol., vol. 26, pp. 523-532, 2011. 
[4] J. Martínez-Vilalta, F. Lloret, and D. D. Breshears, "Drought-induced forest decline: Causes, scope and implications," Biol. Lett., vol. 8, pp. 689-691, 2012.

[5] S. Trumbore, P. Brando, and H. Hartman, "Forest health and global change," Science, vol. 349, pp. 814-818, 2015.

[6] W. R. L. Anderegg, J. M. Kane, and L. D. L Anderegg, "Consequences of widespread tree mortality triggered by drought and temperature stress," Nature Clim. Change, vol. 3, pp. 30-36, 2013.

[7] Impacts of Europe's Changing Climate-2008 Indicator-Based Assessment, European Environment Agency Summary. Report No. 4 /2008, European Environment Agency, Copenhagen, Denmark, 2008.

[8] J. Carnicer, M. Coll, M. Ninyerola, X. Pons, G. Sánchez, and J. Peñuelas, "Widespread crown condition decline, food web disruption, and amplified tree mortality with increased climate change-type drought," Proc. Nat. Acad. Sci., vol. 108, pp. 1474-1478, 2011.

[9] A. C. Bennett, N. G. McDowell, C. D. Allen, and K. J. Anderson-Teixeira, "Larger trees suffer most during drought in forests worldwide," Nature Plants, vol. 1, 2015, Art. no. 15139.

[10] J. C. Linares, J. J. Camarero, and J. A. Carreira, "Competition modulates the adaptation capacity of forests to climatic stress: Insights from recent growth decline and death in relict stands of the Mediterranean fir Abies pinsapo," J. Ecol., vol. 98, pp. 592-603, 2010.

[11] A. Vilà-Cabrera, J. Martínez-Vilalta, L. Galiano, and J. Retana, "Patterns of forest decline and regeneration across scots pine populations," Ecosystems, vol. 16, pp. 323-335, 2013.

[12] R. J. Klos, G. G. Wang, W. L. Bauerle, and J. R. Rieck, "Drought impact on forest growth and mortality in the southeast USA: An analysis using forest health and monitoring data," Ecol. Appl., vol. 19, pp. 699-708, 2009.

[13] A. Vilà-Cabrera, J. Martínez-Vilalta, J. Vayreda, and J. Retana, "Structural and climatic determinants of demographic rates of Scots pine forests across the Iberian Peninsula," Ecol. Appl., vol. 21, pp. 1162-1172, 2011.

[14] P. Ruiz-Benito, E. R. Lines, L. Gómez-Aparicio, M. A. Zavala, and D. A. Coomes, "Patterns and drivers of tree mortality in Iberian Forests: Climatic effects are modified by competition," PLOS ONE, vol. 8, no. 2, p. e56843, 2013.

[15] J. N. Stokland, S. M. Tomter, and U. Soderberg, "Development of dead wood indicators for biodiversity monitoring: Experiences from scandinavia. monitoring and indicators of forest biodiversity in Europe-From ideas to operationality," EFI Proc., vol. 51, pp. 207-226, 2005.

[16] N. G. Mc Dowell et al., "Global satellite monitoring of climateinduced vegetation disturbances," Trends Plant Sci., vol. 20, pp. 114-123, 2015.

[17] Y.H. Kerr et al., "The SMOS mission: New tool for monitoring key elements of the global water cycle," Proc. IEEE, vol. 98, no. 5, pp. 666687, May 2010.

[18] K. D. McMullan et al., "SMOS: The payload," IEEE Trans. Geosci. Remote Sens., vol. 46, no. 3, pp. 594-605, Mar. 2008.

[19] BEC (Barcelona Expert Center). BEC-SMOS-0001-PD. Products Description, BEC 2015-06-18. (2015).[Online]. Available: http://cp34bec.cmima.csic.es/products-documentation/

[20] Y. Kerr et al., "The SMOS soil moisture retrieval algorithm," IEEE Trans. Geosci. Remote Sens., vol. 50, no. 5, pp. 1384-1403, May 2012.

[21] R. Rahmoune, P. Ferrazzoli, Y. K. Singh, Y. H. Kerr, P. Richaume, and A. Al Bitar, "SMOS retrieval results over forests: Comparisons with independent measurements," IEEE J. Sel. Topics Appl. Earth Observ. Remote Sens., vol. 7, no. 9, pp. 3858-3866, Sep. 2014.

[22] A. González-Zamora, N. Sánchez, J. Martínez-Fernández, A. Gumuzzio, M. Piles, and E. Olmedo, "Long-term SMOS soil moisture products: A comprehensive evaluation across scales and methods on the Duero Basin (Spain)," Phys. Chem. Earth, Parts A/B/C, vols. 83/84, pp. 123-136, 2015.

[23] O. Merlin, Y. Malbéteau, Y. Notfi, S. Bacon, S. E-R. Khabba, and L. Jarlan, "Performance metrics for soil moisture downscaling methods: Application to DISPATCH data in central morocco," Remote Sens., vol. 7, pp. 3783$3807,2015$.

[24] O. Merlin, J. P. Walker, A. Chehbouni, and Y. Kerr, "Towards deterministic downscaling of SMOS soil moisture using MODIS derived soil evaporative efficiency," Remote Sens. Environ., vol. 112, pp. 2500-2512, 2008.

[25] O. Merlin, A. Al Bitar, J. P. Walker, and Y. Kerr, "An improved algorithm for disaggregating microwave-derived soil moisture based on red, near-infrared and thermal-infrared data," Remote Sens. Environ., vol. 114, pp. 2305-2316, 2010.
[26] N. N. Das and D. Entekhabi, "An algorithm for merging SMAP radiometer and radar data for high resolution soil-moisture retrieval," IEEE Trans. Geosci. Remote Sens., vol. 49, no. 5, pp. 1504-1512, May 2011.

[27] M. Piles et al., "Downscaling SMOS-derived soil moisture using MODIS visible/infrared data," IEEE Trans. Geosci. Remote Sens., vol. 49, no. 9, pp. 3156-3166, Sep. 2011.

[28] J. Kim and T. S. Hogue, "Improving spatial soil moisture representation through integration of AMSR-E and MODIS products," IEEE Trans. Geosci. Remote Sens., vol. 50, no. 2, pp. 446-460, Feb. 2012.

[29] B. Fang and V. Lakshmi, "Soil moisture at watershed scale: Remote sensing techniques," J. Hydrol., vol. 516, pp. 258-272, 2014.

[30] M. Piles et al., "A downscaling approach for SMOS land observations: Evaluation of high resolution soil moisture maps over the Iberian Peninsula," IEEE J. Sel. Topics Appl. Earth Observ. Remote Sens., vol. 7, no. 9, pp. 3845-3857, Sep. 2014.

[31] S. Sánchez-Ruiz, M. Piles, N. Sánchez, J. Martínez-Fernández, M. Vall-llossera, and A. Camps, "Combining SMOS with visible and near/shortwave/thermal infrared satellite data for high resolution soil moisture estimates," J. Hydrol., vol. 516, pp. 273-283, 2014.

[32] S.K. Tomer et al., "Retrieval and multi-scale validation of soil moisture from multi-temporal SAR data in a tropical region," Remote Sens., vol. 7, no. 6, pp. 8128-8153, 2015.

[33] MODIS Web. National Aeronautics and Space Administration. (2013). [Online]. Available: http://modis.gsfc.nasa.gov/

[34] BEC (Barcelona Expert Centre). CP34-BEC: BEC data distribution and visualization services. 2012-2015. (2015). [Online]. Available: http://cp34-bec.cmima.csic.es/data/data-access

[35] M. Banqué, J. Vayreda, and J. Martínez-Vilalta, Monitoreo del decaimiento de bosques de Cataluña: Proyecto DEBOSCAT. $6^{\circ}$ Congreso Forestal Español, 2013.

[36] L. Galiano, J. Martínez-Vilalta, and F. Lloret, "Drought-induced multifactor decline of Scots pine in the Pyrenees and potential vegetation change by the expansion of co-occurring oak species," Ecosystems, vol. 13, pp. 978-991, 2010.

[37] A. S. Jump, J. M. Hunt, and J. Peñuelas, "Rapid climate change-related growth decline at the southern range edge of Fagus sylvatica," Global Change Biol., vol. 12, pp. 2163-2174, 2006.

[38] M. Ninyerola, X. Pons, J. M. Roure, J. Martín-Vide, J. M. Raso-Nadal, and P. Clavero, Atles Climàtics de Catalunya [1 CD-ROM], Servei Meteorològic de Catalunya, Barcelona, Spain, 2003.

[39] V. Altava, Caracterització i Monitoratge De Les Sequeres a Catalunya $i$ Nord Del País Valencià. Càlcul D'escenaris Climàtics Per Al Segle XXI, Universitat de Barcelona, Barcelona, Spain, 2010.

[40] SMC (Servei Meteorològic de Catalunya). Butlletí estacional. (2012). [Online]. Available: http://www.meteo.cat/wpweb/climatologia/el-climaara/butlleti-estacional

[41] CREAF \& Generalitat de Catalunya. Mapa de Cobertes del Sòl de Catalunya $3^{\mathrm{a}}$ edició, versió 2 (2005-2007). [Online]. (2005). Available: http://www.creaf.uab.es/mcsc/usa/index.htm

[42] F. Lloret, A. Solé, J. Vayreda, and J. Terradas, Atles De Les Plantes Llenyoses Dels Boscos De Catalunya. Barcelona, Spain: Lynx Edicions, 2009, p. 192.

[43] M. Banqué, J. Vayreda, and J. Martínez-Vilalta, Decaïment Dels Boscos De Catalunya (DEBOSCAT) 2012, Centre de Recerca Ecològica i Aplicacions Forestals, Barcelona, Spain, 2013.

[44] R. Sánchez de Dios, M. Benito-Garzón, and H. Sainz-Ollero, "Hybrid zones between two European oaks: A plant community approach," Plant Ecol., vol. 187, pp. 109-125, 2006.

[45] IGC. Institut Geològic de Catalunya. Mapa Geològic de Catalunya. (2006). [Online]. Available: http://www.igc.cat/web/en/igc_cataleg

[46] T. B. McKee, N. J. Doesken, and J. Kleist, "The relationship of drought frequency and duration to time scales," presented at the 8th Conf. Appl. Climatol., Anaheim, CA, USA, 1993.

[47] J. M. Escorihuela, A. Chanzy, J. P. Wigneron, and Y. H. Kerr, "Effective soil moisture sampling depth of L-band radiometry: A case study," Remote Sens. Environ., vol. 114, no. 5, pp. 995-1001, 2010.

[48] M. Piles. (2010). Multiscale soil moisture retrievals from microwave remote sensing observations. Ph.D. dissertation, Dept. de Teoria del Senyal i Comunicacions, Universitat Politècnica de Catalunya. Barcelona, Spain. [Online]. Available: http://www.tdx.cat/handle/10803/ 77910

[49] S. Chan, R. Bindlish, R. Hunt, T. Jackson, and J. Kimball, Soil Moisture Active Passive (SMAP). Ancillary Data Report. Vegetation Water Content, Jet Propulsion Laboratory, California Institute of Technology, Pasadena, CA, USA, 2013. 
[50] C. H. Albert and W. Thuiller, "Favourability functions versus probability of presence: Advantages and misuses," Ecography, vol. 31, pp. 417-422, 2008.

[51] D. W. Hosmer and S. Lemeshow, Applied Logistic Regression, 2nd ed. New York, NY, USA: Wiley, 2000.

[52] S. M. Vicente-Serrano et al., "Response of vegetation to drought timescales across global land biomes," Proc. Nat. Acad. Sci., vol. 110, pp. 52-57, 2013.

[53] A. P. Williams et al., "Temperature as a potent driver of regional forest drought stress and tree mortality," Nature Clim. Change, vol. 3, pp. 292 297, 2012.

[54] L. D. L. Anderegg, W. R. L. Anderegg, J. Abatzoglou, A. M. Hausladen, and J. A. Berry, "Drought characteristics' role in widespread aspen forest mortality across Colorado, USA," Global Change Biol., vol. 19, pp. 15261537,2013

[55] B. Choat et al., "Global convergence in the vulnerability of forests to drought," Nature, vol. 491, pp. 752-756, 2012.

[56] B. M. J. Engelbrecht et al., "Drought sensitivity shapes species distribution patterns in tropical forests," Nature, vol. 447, pp. 80-83, 2007.

[57] J. Martínez-Vilalta et al., "Las poblaciones ibéricas de pino albar ante el cambio climático: Con la muerte en los talones," Ecosistemas, vol. 21, pp. 15-21, 2012.

[58] T. J. Brodribb, J. Pittermann, and D. A. Coomes, "Elegance versus speed: Examining competition between conifer and angiosperm trees," Int. J. Plant Sci., vol. 173, pp. 673-694, 2012.

[59] M. Banqué, J. Vayreda, and J. Martínez-Vilalta, Decaïment Dels Boscos De Catalunya (DEBOSCAT) 2013, Centre de Recerca Ecològica i Aplicacions Forestals, Barcelona, Spain, 2014.

[60] A. M. Heres, J. Martínez-Vilalta, and B. Claramunt, "Growth patterns in relation to drought-induced mortality at two Scots pine (Pinus sylvestris L.) sites in NE Iberian Peninsula," Trends Ecol. Evol., vol. 26, pp. 621-630, 2012.

[61] F. Lloret, A. Escudero, J. M. Iriondo, J. Martínez-Vilalta, and F. Valladares, "Extreme climatic events and vegetation: The role of stabilizing processes," Global Change Biol., vol. 18, pp. 797-805, 2012.

[62] J. Martínez-Vilalta and J. Piñol, "Drought-induced mortality and hydraulic architecture in pine populations of the NE Iberian Peninsula," Forest Ecol. Manage., vol. 161, pp. 247-256, 2002.

[63] E. S. Meier, T. C. Edwards, Jr., F. Kienast, M. Dobbertn, and N.E. Zimmermann, "Co-occurrence patterns of trees along macro-climatic gradients and their potential influence on the present and future distribution of Fagus sylvatica L," J. Biogeogr., vol. 28, pp. 371-382, 2011.

[64] WorldClim-Global Climate Data. (2014, Dec. 2). [Online]. Available: www.worldclim.org

[65] W. R. L. Anderegg et al., "Tree mortality from drought, insects, and their interactions in a changing climate," New Phytologist, vol. 208, no. 3, pp. 674-683, 2015.

[66] R. B. Jackson, J. Canaell, J. R. Ehleringer, H. A. Mooney, O. E. Sala, and E. D. Schulze, "A global analysis of root distributions for terrestrial biomes," Oecologia, vol. 108, pp. 389-411, 1996.

[67] M. Rodell et al., "The global land data assimilation system," Bull. Amer. Meteorol. Soc., vol. 85, pp. 381-394, 2004, doi:10.1175/BAMS-85-3-381.

[68] C. Albergel et al., "From near-surface to root-zone soil moisture using an exponential filter: An assessment of the method based on in-situ observations and model simulations," Hydrol. Earth Syst. Sci., vol. 12, pp. 1323-1337, 2008.

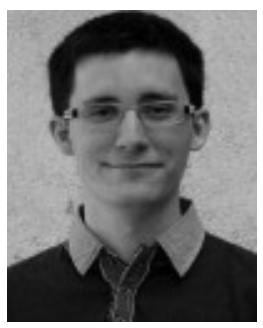

David Chaparro (S'14) was born in Barcelona, Spain, in 1988. He received the M.S. degree in biology from the Universitat Autònoma de Barcelona (UAB), Barcelona, in 2011, the M.S. degree in remote sensing and GIS from the Centre of Ecological Resarch and Forestry Applications, Barcelona, in 2012, and the M.S. degree in terrestrial ecology and biodiversity management from the UAB in 2013. In 2014, he joined the Department of Signal Theory and Communications at the Universitat Politècnica de Catalunya, Barcelona, as a Ph.D. Student.

His research is based on the development of environmental applications from microwave satellite data such as forest health and wildfires risk assessment.

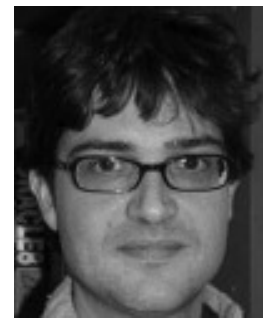

Jordi Vayreda received the M.S. degree in biology from the Universitat de Barcelona, Barcelona, Spain, in 1990, and the M.S. degree in terrestrial ecology and biodiversity management and the Ph.D. degree in terrestrial ecology from the Universitat Autònoma de Barcelona, Barcelona, in 2010 and 2012, respectively.

Since 1995, he has been a Researcher with the Centre for Ecological Research and Forestry Applications, Barcelona. He has been in charge of the calculation and analysis of information from national forest inventories and the management of these large databases. He has developed software applications to help users to make queries about this information through Internet. He has been responsible for several reports commissioned by the Government on the use of forest biomass for energy and the calculation of carbon stocks and carbon balance of Spanish and Catalan forests. His research interests include macroecology on the impacts of disturbances and global change in forests (die-off, vulnerability, resilience, and biodiversity): demography, carbon balance, growth, mortality, and regeneration at large scale. Among his research experience, there are vulnerability and resilience of forests at large scale to global change, forest information obtained from the LiDAR technology, structure and dynamics of forest communities, forest die-off and regeneration, forest databases, design and management of large databases, and development of query tools of forest information.

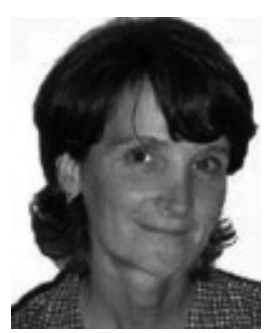

Mercè Vall-llossera (SM'99) received the M.S. and $\mathrm{Ph} . \mathrm{D}$. degrees in telecommunications engineering from the Universitat Politècnica de Catalunya (UPC), Barcelona, Spain, in 1990 and 1994, respectively.

She was lecturing and doing research with the Department of Signal Theory and Communications, UPC, from 1990 to 1997, as an Assistant Professor, and currently as an Associate Professor from 1997. She spent a sabbatical year with the Concordia University, Montreal, QC, Canada, with the scholarship of the "Programme Québécois de Bourses, d'excellence" (1996-1997): "Stages de Formation postdoctorale au Québec pour jeunes diplomés étrangers" applying the FDTD method in the analysis of the effect of mobile telephone to the body. She has been participating in several projects for the preparation of the SMOS mission by ESA. Her research interests include passive remote sensing and retrieval of geophysical parameters from radiometric measurements.

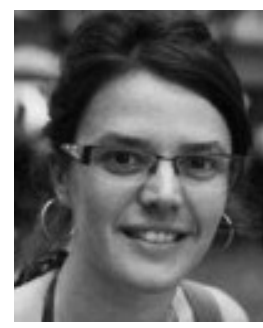

Mireia Banqué was born in Barcelona, Spain, in 1983. She received the M.S. degree in environmental sciences from the Universitat de Barcelona, Barcelona, in 2007, and the M.S. degree in GIS and remote sensing from the Universitat Autònoma de Barcelona, Barcelona, in 2007.

In 2008, she joined the Centre for Ecological Research and Forestry Applications, Barcelona, as a Technician working on the Land Cover Map of Catalonia (MCSC), performing photointerpretation tasks. In 2010, she joined Dr. Vayreda and Dr. Martínez-Vilalta team, where she specialized on forest decline associated with global change, especially with drought die-off events. Some of their projects (e.g., DEBOSCAT and CANVIBOSC) have direct applicability on forest management by Environmental Agencies. Since late 2013, their team research interest includes ecosystem services and their valorization, a promising way to improve conservation and ecosystem management. 


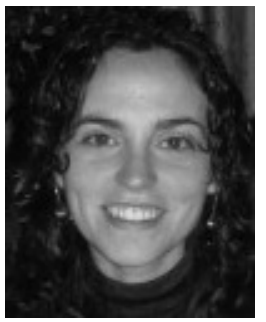

Maria Piles (S'05-M'11) was born in Valencia, Spain, in 1982. She received the M.S. degree in telecommunication engineering from the Universitat Politècnica de València, València, in 2005, and the $\mathrm{Ph} . \mathrm{D}$. degree in telecommunication engineering from the Universitat Politècnica de Catalunya (UPC), Barcelona, Spain, in 2010.

In 2010, she joined the Department of Civil and Environmental Engineering, University of Melbourne, Melbourne, Australia, as a Research Fellow. From 2011 to 2015, she was a Research Scientist at the Department of Signal Theory and Communications, UPC, actively participating at the Barcelona Expert Center activities. During these years, she was also a Research Affiliate with the Department of Civil and Environmental Engineering, Massachusetts Institute of Technology, Boston, USA. Since 2015, she has been a Research Scientist at the Institute of Marine Sciences, CSIC, Barcelona. She has published 25 papers in international peer-reviewed journals, two book chapters, and more than 65 international conference presentations. Her research interests include the retrieval of soil moisture and vegetation geophysical parameters from space observations (microwave radiometers, radars, and hyperspectral imagers), and the development of multisensor downscaling techniques.

Dr. Piles received the Med-Storm Prize for Young Researchers in the Plinius Conference in 2011 and the UPC special doctoral award in Information Technology and Communication in 2012. She has participated in ten projects (six national, four international) and has advised eight M.Sc. theses and two Ph.D. theses (underway). Since 2012, she has been a Board Member of the IEEE Geoscience and Remote Sensing Society Spanish Chapter.

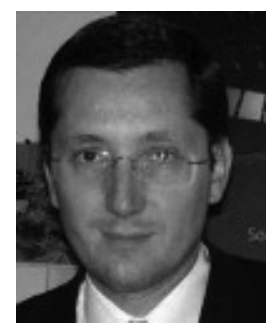

Adriano Camps (S'91-A'97-M'00-SM'03-F'11) was born in Barcelona, Spain, in 1969. He received the M.S. and Ph.D. degrees in telecommunications engineering from the Universitat Politècnica de Catalunya (UPC), Barcelona, in 1992 and 1996, respectively.

In 1991 to 1992, he was with the ENS des Télécommunications de Bretagne, France, with an Erasmus Fellowship. Since 1993, he has been with the Electromagnetics and Photonics Engineering Group, Department of Signal Theory and Communications, UPC, where he was an Assistant Professor, an Associate Professor in 1997, and has been a Full Professor since 2007. In 1999, he was on sabbatical leave with the Microwave Remote Sensing Laboratory, University of Massachusetts, Amherst, MA, USA. Since 1993, he has been deeply involved in the European Space Agency SMOS Earth Explorer Mission, and since 2001, on the use of GNSS-R techniques to perform the sea state correction needed to retrieve salinity from radiometric observations. He has published more than 125 peer-reviewed journal papers, and more than 250 international conference presentations.

Dr. Camps has received a number of awards for his research and teaching activities, among which the Research Distinction of the Generalitat de Catalunya in 2002 for contributions to microwave passive remote sensing; the European Young Investigator Award in 2004 of the European Science Foundation, the ICREA Academia award in 2009, and the 1st and 7th Duran Farell Awards in 2000 and 2010 , respectively.

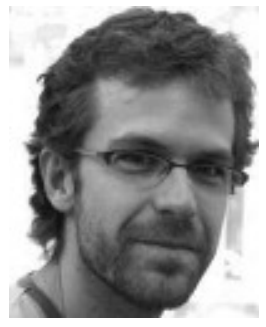

Jordi Martínez-Vilalta was born in Barcelona, Spain, in 1975. He received the M.S. and Ph.D. degrees in environmental sciences from the Universitat Autònoma de Barcelona (UAB), Barcelona, in 1997 and 2001, respectively.

$\mathrm{He}$ is currently a Senior Lecturer at $\mathrm{UAB}$, and a Researcher at the Centre for Ecological Research and Forestry Appliations, Barcelona. His research interest includes improving our understanding of the functioning of natural systems and their responses to environmental changes. His work is focused on the study of plant communities, particularly forests, and emphasizes drought impacts in the context of climate change; an area in which he has coordinated many research projects.

Dr. Martínez-Vilalta has been a Honorary Fellow at the University of Edimburg, Edimburg, U.K. He received an ICREA award in 2014. He is a Member of the Editorial Review Board of the journals the Tree Physiology, the iForest, and the ISRN Ecology, and an Associate Editor of the Journal of Plant Hydraulics. 